\title{
Ambient co-presence: transnational family practices in polymedia environments
}

\author{
MIRCA MADIANOU \\ Goldsmiths, University of London \\ m.madianou@gold.ac.uk
}

\begin{abstract}
In this article, I develop an argument about a new type of mediated co-presence termed 'ambient co-presence', which is the peripheral, yet intense awareness of distant others made possible through the affordances of ubiquitous media environments. Drawing on a long-term ethnography of UK-based Filipino migrants and their communication practices with their transnational families, I observe the increasing prevalence of an 'always on' culture of ubiquitous connectivity. The functions of a social networking site (SNS) such as the 'news feed', combined with the portability of internet-enabled devices and locative services, mean that users can be peripherally, yet constantly aware of the actions and daily rhythms of their peers. This peripheral awareness, which can be pervasive, complements other types of mediated co-presence and has powerful emotional consequences - both positive and negative for relationships at a distance. Participants with weak relationships reported an increase in conflict especially through opportunities for surveillance. By contrast, those who enjoyed strong relationships associated ambient co-presence with low-level emotional reassurance. In this article, I also observe that ambient co-presence has implications for community and belonging. Notwithstanding the development of online norms that are culturally specific, I argue that the concept of ambient co-presence can have cross-cultural relevance for understanding the consequences of mediated communication.
\end{abstract}

Keywords SOCIAL MEDIA, WEBCAM, TRANSNATIONAL FAMILIES, INTIMACY AT A DISTANCE, SMARTPHONES, LOCATIVE MEDIA, ETHNOGRAPHY

This article identifies a new type of mediated co-presence, which is made possible by recent developments in contemporary media environments and changes in user habits and patterns of appropriation. 'Ambient co-presence' is the increased awareness of the everyday lives and activities of significant others through the background presence of ubiquitous media environments. While most forms of mediated co-presence rely on mediated interaction, ambient co-presence results from a more peripheral awareness of

This is an open access article under the terms of the Creative Commons Attribution License, which permits use, distribution and reproduction in any medium, provided the original work is properly cited.

Global Networks 16, 2 (2016) 183-201. ISSN 1470-2266. (C) 2016 The Author(s)

Global Networks C 2016 Global Networks Partnership \& John Wiley \& Sons Ltd 
distant others enabled by technological convergence and the affordances of social and mobile media. This peripheral awareness, which can be pervasive, complements other types of mediated co-presence and has powerful emotional consequences for relationships at a distance, such as those maintained by transnational families.

For this article, I draw on long-term ethnographic work on UK-based Filipino migrants' transnational communication practices with their left-behind families, including their children, for whom mediation and co-presence are important issues. While most people experience a combination of mediated communication and face-to-face co-presence in their daily interactions, transnational families depend heavily, if not entirely, on communication technologies to maintain relationships at a distance. Given that some family members may be separated for years (Baldassar et al. 2007; Madianou and Miller 2012), mediated communication can be vital for distant caregiving and a potential lifeline for the survival of the relationships. The convergence of transnationalism and communication technologies has enabled sets of practices that support a new type of 'connected family' at a distance, which has wider implications for the phenomenon of migration itself (Madianou 2012). This article offers a detailed account of a new type of mediated co-presence made possible by the emergence of communication environments of polymedia (Madianou and Miller 2013).

Migrants are often at the forefront of technological developments because of their dependency on such innovations to maintain long distance relationships. Of course, there are huge variations among migrant experiences, but for UK-based migrants from the Philippines, despite digital inequalities and a persisting 'care divide' (Madianou 2014), there is evidence of strong technological uptake. The almost extreme conditions of separation and media dependency that migrants experience may reveal aspects of mediation that are relevant to wider populations. Although this article is about transnational family communication, the argument about ambient co-presence may have wider applicability.

I shall now examine transnational family communication before going on to discuss the particular affordances of the new media environments that enable ambient copresence.

\section{Transnational family relationships and mediated communication}

Families separated because of work are not a new phenomenon (Thomas and Znaniecki 1984), but in recent years, we have witnessed quantitative and qualitative changes for various reasons, including the intensification and feminization of global migration (Parreñas 2001). That women from countries in the 'global South' are as likely, if not more likely, to migrate than men, and that these women are often mothers has given rise to the phenomenon of 'transnational mothering' (Hondagneu-Sotelo and Avila 1997; Parreñas 2001). Although several types of transnational family arrangements exist, scholars usually describe left-behind children and their separation from their mothers in the most poignant terms. The Philippines exemplifies this phenomenon with over nine million overseas workers and nine million left-behind children (Parreñas 2008: 68). Although elsewhere I have focused on the contours of transnational 
mothering (Madianou 2012), in this article I explore the wider sets of family and intimate relationships that Filipina migrant women maintain - including those with their left-behind children.

Transnational families exemplify the recent theorization of family as 'sets of practices' rather than a static structure or entity (Morgan 1996). The deterritorialized nature of transnational families shifts our attention away from traditional definitions of family as a place-bound unit and crystallizes its nature as constituted through a set of activities that acquire meaning under particular circumstances. In this sense family is better understood as a verb ('doing family') rather than a noun (Morgan 1996). In the absence of physical co-presence, transnational family members can only be part of the family through the daily actions that are typically mediated by communication technologies. Communication practices, such as making a phone call or sending a text message, become the key practices - or 'fragments of daily life' (Morgan 1996: 190) through which family comes into being. Such practices pertain to all types of families (Wajcman et al. 2008), but are accentuated in transnational ones. We should not, however, romanticize the role of communication technologies for 'doing family' because, as with non-mediated practices, acts of mediated communication can have complex consequences, both positive and negative, depending on a number of factors, including the relationships themselves.

Given transnational families' dependency on mediated communication it is surprising that migration research neglected the role of communication technologies for years. This has changed recently with what is now a substantial body of work which has analysed communication as integral to transnational family practices (Baldassar 2008; Cabanes and Acedera 2012; King-O'Riain 2014; Madianou 2012; Madianou and Miller 2012; Nedelcu 2012; Parreñas 2005; Peng and Wong 2013; Uy-Tioco 2007; Wilding 2006). Studies have highlighted different aspects of the role of mediated communication - both negative and positive - for transnational relationships such as the way they amplify gender asymmetries (Parreñas 2005), facilitate emotional expression (Baldassar 2008; King-O'Riain 2014) and relate to identity processes (Nedelcu 2012).

What remains relatively undertheorized in migration and transnational families research is the nature of communication technologies. This matters because communication media are not static conveyors of content, but technologies with complex 'architectures' (Papacharissi 2009) that facilitate some types of interaction and not others. Understanding the nature of different communication technologies and how these constitute larger media environments is essential for comprehending their consequences for transnational family practices. In this article I adopt a sociotechnical approach to communication technologies to develop an understanding of mediated co-presence for transnational family relationships.

\section{Mediated co-presence and polymedia environments}

Co-presence was traditionally understood as synonymous with face-to-face interaction and superior to mediated interactions. Mediation, in this vein, was considered a form 
of impoverishment compared to the gold standard of face-to-face communication (for a discussion see Baym 2010). In the early days, textual internet-mediated communication suffered from reduced social cues containing emotional information, which is essential for meaningful personal communication (Baym 2010: 51-6). Even when communication technologies evolved, notions that mediation is inferior compared to face-to-face interaction have persisted generating anxieties about web use and its consequences for interpersonal relationships (Turkle 2011).

The proliferation of new communication technologies has given rise to new, potentially rich interactions at a distance, which largely overcome some of the constraints associated with earlier forms of mediated communication. New media offer a range of affordances, namely the opportunities for action afforded by a particular technology or platform (Hutchby 2001), which provide a rich texture for personal communication (Harper 2010). Recent research highlights the varied ways in which users employ digital media for personal communication (Baym 2010) and supplement face-to-face interactions. Rather than undermining the quality of relationships, studies have found that people with strong bonds tend to use more media, more frequently in order to sustain their relationships (Haythornthwaite 2005). In a recent study of communication practices among transnational families, we put forward a theory of polymedia to the effect that new media operate as environments of affordances that users navigate with a view to managing their relationships (Madianou and Miller 2012).

Polymedia theory understands media as part of a composite environment in which each medium is defined relationally to all other media. In the past, when people relied too heavily on a single technology such as letters, the particular properties of the technology or medium shaped interactions in specific ways. For instance, the time lag of letters meant that 'news' was always several weeks old. The temporality of letters caused frustration among letter writers (Madianou and Miller 2012). By contrast, when users have access to dozens of different applications, platforms and devices, they can easily exploit the qualities of each to compensate for the limitations of other platforms. Polymedia shift the emphasis from discrete technologies or platforms to media environments. Rather than focus on the properties or affordances (Hutchby 2001) of specific technologies, polymedia shift our attention to how users navigate media environments and choose platforms from a range of communicative opportunities. Choosing a medium from among the several available options requires emotional intent and becomes key to how people manage their relationships (Madianou and Miller 2013). For example, those desiring to introduce some distance in a relationship may choose email because of its asynchronous nature.

The temporal structure of communication technologies is one of the many affordances that sustain different types of mediated co-presence. In this article, I argue that increasing technological convergence within polymedia environments is facilitating a new type of co-presence, which I call 'ambient co-presence'. Unlike other types of mediated interaction, 'ambient co-presence' is not based on direct interactions but on the peripheral awareness of the actions of distant others, made possible through the affordances of polymedia environments. The term 'ambient' has already been used to capture changes in journalism (Hermida 2010). Drawing on work in human-computer 
interaction and design (Markopoulos et al. 2009), Hermida analyses Twitter as an 'awareness system' that allows citizens to maintain a 'mental model of news and events around them' and facilitates new kinds of interactions around the news (Hermida 2010: 298). I employ the term 'ambient' here to capture changes in the sphere of personal communication. Below, I briefly outline the evolution of different types of mediated co-presence before detailing the affordances that enable ambient co-presence.

\section{Types of mediated co-presence}

Mediated co-presence evolved alongside communication technologies and associated practices. As new technologies are introduced, media environments become more complex offering users a range of opportunities for being together at a distance. From letter writing to daylong Skype sessions, it is evident that mediated co-presence is continually evolving. Technological innovations bring new possibilities. For example, the portability of mobile phones introduced 'connected presence' (Licoppe 2004). Before the arrival of mobile phones calls were typically made on special occasions or at a set time of the week (such as on a Sunday morning). The popularization of mobile phones changed the frequency of interaction between close family and friends who became continually available to one another through short, frequent calls, the content of which is sometimes secondary to the fact of calling. 'Connected presence' is an ongoing 'dialogue' that helps to 'maintain the feeling of a permanent connection ... that the link can be activated at any time' (Licoppe 2004: 141). Ling and Yttri (2002) have also observed how mobile phones have enabled the continuous micromanaging and micro-coordination of everyday activities.

Of course, before the popularization of wireless services and internet-enabled devices reduced the cost of communication at a distance, which is a relatively recent phenomenon, 'connected presence' was often prohibitively expensive for migrants. Until not so long ago transnational co-presence was largely achieved through ritual calls made through international phone cards (Vertovec 2004), or through objects such as photographs and letters that embodied the absent person. Baldassar (2008: 252) called this indirect form of co-presence, 'co-presence by proxy'. The popularization of social media and smartphone devices have enabled the combination of different types of mediated interaction and co-presence. Polymedia environments often facilitate both 'connected presence' (say through a variety of synchronous platforms like Skype, texting or social media such as Whatsapp) and 'co-presence by proxy' (for example through the visual content one can retrieve through social media). Polymedia environments also facilitate 'ambient co-presence', which is a new, hybrid type of indirect co-presence.

So what are the qualities and affordances of social media that underpin 'ambient co-presence'? The challenge of studying social media is that they resemble moving targets, changing faster than we can study them; in fact, there are already several generations of social networking sites (SNSs). However, the architecture of their structure around the public articulation of personal networks is one feature of an SNS that remains constant. As Ellison and boyd remark, 'the ability to delineate someone 
as a public contact - or "Friend" - and thus create an aggregated list that constitutes one's network on the site is the key differentiating feature of SNSs' (Ellison and boyd 2013: 155). One aspect that has changed more recently is that user profiles are increasingly co-constructed by the content their 'Friends' provide. Facebook, which remains the largest SNS, introduced the functionality of 'news feed', which is effectively a personal news aggregator (Ellison and boyd 2013). News feed is the collection of content produced by one's contacts, or by their contacts' friends. It is a constantly updating list of stories from the people or groups to which a user is connected. News feed stories can include status updates, photographs, videos, links to other sites, records of usage of applications (such as games) and 'likes'. News streams (first introduced in 2006) have become the default greeting page on Facebook and are also a key feature of other SNSs such as Twitter. Users cannot control their feed or how they appear in other people's feeds because other users may mention them or connect ('tag') them to specific content such as photographs. ${ }^{1}$ News feeds are key to ambient co-presence, for information about the activities of others is literally streamed to one's screen on a real-time basis. ${ }^{2}$ Vitak has already acknowledged the role of news feeds in the maintenance of relationships, but unlike Vitak (2014: 17), who sees reading friends' updates as passive content consumption, or 'passive browsing', I argue that ambient co-presence is a dynamic process, integral to the ways in which users navigate the environment of polymedia.

Social networking sites combine different temporal structures. News feeds are streamed in real time 'as content is produced' and, given that content is usually permanent and thus retrievable, SNSs also facilitate asynchronous communication (Tong and Walther 2011). Once status updates or photographs have been uploaded they can be retrieved as long as they are not deleted. Content can also resurface when other users comment on older material or photographs. Overall, the functionalities and technical affordances that characterize SNSs increasingly converge, thus launching new hybrid possibilities for communication. For example, Facebook includes an instant messaging (IM) platform, which allows users to see who is online or offline as well as displaying the time when a user was last active on the site. This synchronous IM platform can be used in parallel to the other synchronous and asynchronous functions of Facebook, thereby creating a complex micro-environment in its own right.

Three further characteristics of polymedia environments are important to our understanding of ambient co-presence; these are visuality, mobility and locative functionality. Social network sites afford users tremendous amounts of visual cues many of which are streamed into the users' news feeds. The increased visuality of an SNS provides useful information to the user's friends. The mobility of social network sites and other new media has enabled people to send and receive messages wherever they are (Baym 2010). The phenomenal rise of smartphones and the popularization of wireless services have produced an 'always on' lifestyle in which people can receive continual updates on their significant others. Being online is no longer tied to a desktop, but continues seamlessly in various settings via a plethora of portable devices and wireless services. Finally, the locative functionality of mobile devices - the fact that internet enabled platforms reveal the geographical location of their users - connects 
online actions to physical places, which was not typically possible with earlier forms of mediated interaction.

In the empirical section of this article, I shall illustrate how these affordances, as part of a communicative environment of polymedia, enable a peripheral awareness of distant others. In the analysis, I consider the emotional consequences of ambient co-presence for transnational relationships. First, however, some context about Filipino transnational families and the actual research is necessary.

\section{The research and empirical contexts}

With over 10 per cent of the population working abroad and more than one million migrants deployed annually (Asis 2008), the Philippines is one of the most intensely migrant societies. Remittances reached 24 billion USD for 2012 making the Philippines one of the top three remittance-receiving countries in the world, behind only China and India, both of which are considerably larger countries (Connor et al. 2013). The dependency of the Philippine economy on remittances explains why migration is a key economic policy for the Philippine government as the state actively promotes and regulates migration (Asis 2008). The demand for care and domestic work in countries like the UK has been one of the factors contributing to increased female migration (Parreñas 2001).

The UK is a popular destination for Filipino workers with conservative estimates of the UK based Filipino population running at 200,000 (POEA 2010). Many migrants arrived between 1999 and the mid-2000s when the UK was actively recruiting nurses from the Philippines to work in the National Health Service. The UK Filipino population also includes domestic workers and nannies, who arrived after stints in the Middle East, and caregivers, who usually came to the UK on student visas, so do not appear in the official statistics. Their solid presence in the care sector suggests that the UK Filipino population is predominantly female as confirmed by earlier reports (POEA 2005). Although there are no official data, my long-term involvement with Filipino communities in England suggests that they tend to be well educated, with even domestic workers often holding college degrees. Although there are occupational divides which map onto digital exclusion - nurses, for example, are much better connected than domestics (as are their largely urban middle class families back home) and thus better equipped for long distance parenting - the arrival of smartphones and cheap netbooks seem to open up the opportunities for transnational communication for the less privileged Filipino migrants.

I have based this article on long-term ethnographic work with Filipino transnational families and on the follow-up fieldwork I undertook to update my earlier research reported elsewhere (Madianou 2012; Madianou and Miller 2012). I here draw primarily on online ethnography and on interviews with 13 UK-based migrants, all of whom were key informants in the previous project (2007-11). The follow-up study took place between 2011 and 2014 and focused on relationship developments and changes in participants' communications environments since the original fieldwork. This was a period of rapid transformation in communication technologies as smartphones, tablets 
and webcam applications became very popular and affordable. Although the follow-up study mainly focuses on 13 interviewees, my understanding of their relationships and communications environments is informed by a seven-year in-depth study of their personal and family histories in particular, and of the wider context of Filipino migration in general. My writing is also informed by interviews with more than 106 participants in the original study. Over the years I have developed a strong rapport with my participants and an intimate understanding of their relationships which compensates for the small sample. Even though the follow up study concentrated on UK participants, the analysis draws on my knowledge of and ongoing connection with the left-behind families who were part of the original ethnography in 2009.

The ages of the 13 migrants, of whom 12 were women, ranged from 22 to 72 years. They worked mainly in nursing and the wider care sector, which incorporated childcare and domestic work. Almost all were college educated including three of the four domestic workers. All had family members, including children, in the Philippines. On average, they visited the Philippines every two years, with nurses visiting more frequently (usually annually). Most had relatives or romantic partners with whom they communicated frequently in other countries such as Australia, Canada, Greece, Saudi Arabia and the United States. I report on these relationships as well as those with their left-behind children.

\section{Ubiquitous connectivity}

The emergence of ubiquitous computing (Dourish and Bell 2011) facilitated by the popularization of wireless services and mobile devices such as smartphones and tablets has given rise to an 'always on' lifestyle (boyd 2012). For those with access to portable internet-enabled devices ${ }^{3}$ the boundaries between online and offline become increasingly blurred, while being online no longer registers as a distinct state (Madianou 2014). An example of being 'always on' is when participants like Donna or Janice check social media applications such as Facebook via their smartphones several times an hour. The default position for participants was to be constantly logged onto popular platforms such as Facebook especially via their portable devices. Checking or updating news on SNS becomes seamlessly woven into other daily practices.

It was not always like this. In 2007, when I first met Janice, a domestic worker, she was attending Sunday IT classes at a community centre to learn how to use email and instant messaging (IM). Shortly thereafter she started to visit internet cafés for emailing and IM, but the inconvenience of having to go to a café made Janice rely on texting via her mobile phone to keep in touch with her family. She was a prolific SMS writer. In 2010, she joined Facebook and purchased her first netbook, which she used with an internet dongle. She kept her netbook on the kitchen counter where she worked as a cook and often chatted with several of her Facebook friends simultaneously while attending to other tasks. In 2013, Janice bought her first smartphone, which has effectively replaced her netbook because it has enabled her to access her favourite platforms on the move while she is also able to take and upload photographs several times a day. Having worked with the same migrants for seven years has enabled me to 
witness the changes in their media landscapes. Janice's example is typical of most of the subjects in this study.

Smartphones are a major factor contributing to the ubiquitous connectivity of my respondents, most of whom had acquired an internet-enabled mobile device by 2014 . Nurses were the first to use smartphones, but most of the domestic workers followed suit. For live-in domestic workers, smartphones are particularly vital in that they facilitate web connectivity in the absence of other bulkier equipment that is harder to maintain in the limited space of a small room, which is the usual living arrangement. For nurses smartphones also make a difference given nurses' unpredictable schedules, which typically include night, or long shifts. Although the occupational divides among migrants' digital footprints persist, smartphones have softened some of the access divides between nurses and domestic workers (for a discussion see Madianou 2014).

Maria-Theresa, a nurse, lives in a small bedsit in London. Her laptop and smartphone are always on the desk by her bed and never switched off. She is always logged onto various platforms such as Skype and Facebook - day and night. She often works night shifts and sleeps during the day. Maria-Theresa is often woken by the sound of one of her Skype contacts - usually her boyfriend or one of her brothers who work in the Middle East - appearing online. Occasionally she chats with them before attempting to sleep again, but even if they do not speak with each other the sound of her boyfriend or brother coming online is reassuring. The green tick of the online status accompanied by the familiar sound carries much information in its own right. The online status sound of a significant other provides reassurance that familiar routines are being followed and that everything is OK. The absence of such a sound, by contrast, is a deviation from routine and reason for worry. Maria-Theresa finds such absences more disruptive than the actual noise that might wake her at $4.00 \mathrm{a} . \mathrm{m}$. She has learnt to expect the sound and then to ignore it. It is clear that there is a monitoring function here to which we shall return later. It is clear from Maria-Theresa's story that she develops a strong sense of her distant family's routines and rhythms without interacting with them directly, but rather by observing them appear - and disappear - online. This becomes possible because of her 'always on' lifestyle combined with the technical affordances of her media environment.

\section{From connected presence to ambient co-presence}

Donna is the mother of two teenage sons and a four-year old daughter. She has been an avid communicator throughout her migration maintaining daily contact with her left-behind family using a wide range of platforms. In 2009, she used her feature phone daily, mainly to send text messages but also to make short calls through a dedicated package for international calls. The texts and calls coordinated household activities, as is typical in 'connected presence' (Licoppe 2004). For example, she would text her son to remind him to take his medication. Some of her text messages had a more phatic function, simply aiming to reaffirm the relationship. Donna also used Skype daily for longer conversations and richer interactions (such as playing 
games with her baby daughter) and would even leave the webcam on for hours during the weekends.

Since obtaining a smartphone in 2011, Donna has been relying heavily on Facebook to get a sense of the lives of her children, especially her two teenage sons who are keen users. Like Maria-Theresa, Donna is perpetually logged onto Facebook through her smartphone, which she checks several times a day for status updates and other notifications. The constant stream of information through social media now often replaces other mediated interactions, such as the daily Skype call, which has become more infrequent but is still regular (at least twice a week and certainly at weekends). Even though Donna may not speak to her sons for two or three days, she stills knows a great deal about her children through her news feed. Her sister, who together with their mother look after Donna's children, posts photographs several times a week. Donna's news feed is a stream of images of family meals, outings, dishes (especially desserts), her daughter's new clothes, toys or drawings, and scanned images of her sons' school reports. These photographs, comments and status updates 'do family' (Morgan 1996) and provide an ambient background to Donna's daily life. Although Donna's voice communication is less frequent than it was when her boys were younger, she continues to be as up-to-date with her family's activities as she had always been. The difference is that much of her knowledge today is derived through indirect interactions - her sons' status updates, their postings on their friends' walls, the photos they are tagged in and their 'likes'. Donna is not the intended audience of much of this communication, yet this is a rich source of information about her two sons.

The reasons why Donna's communication patterns have changed are likely to be more complex than simply because of a shift in technological affordances. Her sons are now teenagers, so are less likely to be available for chats with their parents than younger children would be (Ling and Yttri 2002). Additionally, Donna's prolonged migration has meant that the family remains separated for six years, which may also have had a cumulative effect on their communication habits. None of these factors, however, seems to have lessened Donna's desire to know what her children are doing. Her heavy use of social media, particularly Facebook, is devoted largely to maintaining family bonds such as commenting on photographs of her children and relatives and posting about how much she misses them. On Sundays Donna and her family still enjoy long video calls. These sessions are a hybrid between a webcam call and simply being together at a distance. A session often begins with direct interactions, but sometimes continues without the participants interacting directly.

These mediated practices are how Donna and her children 'do family' (Morgan 1996), reminding us that families are not a static entity but are constituted through their practices. Transnational families such as Donna's develop a range of mediated practices through which they can construct co-presence and meaning. Mediated co-presence via webcam, as well as via other media, continues in parallel to ambient co-presence. The different types of mediated interaction supplement each other and provide participants' with a complex environment through which they can be together. 


\section{'Checking in': locative media and ambient co-presence}

Locative media are the networked services available on internet-enabled portable devices that provide users with 'a reflexive awareness of the location of themselves and others or their mutual proximity' (Licoppe 2013: 123). Locative media can either depend on technologically calculated software (such as GPS and wireless broadband geolocation services operated by mobile phone providers) or in a 'declarative manner' via locationsharing applications such as Facebook 'check-ins' (Licoppe 2013: 123). Both options are widely used in the mobile phone apps of popular social media such as Facebook and Twitter. Geolocating messages was the default option for most participants when using the Facebook mobile app, which is the standard way to access Facebook through a smartphone. In addition, several respondents actively chose to 'check-in' places they visited. This almost always included special places (for example, a visit to the London Olympic Park during the summer of 2012) but also ordinary, everyday places like shops or restaurants. 'Checking-in' is more intentional compared to automatically geolocated messages although some intention can be attributed in configuring the device settings to geolocate messages by default. Still, given that many participants don't even know how to change such settings, geolocation is often the result of smartphone 'information leakage'. Yet, no respondents expressed concern about the leaking of personal information without their consent. On the contrary, they usually embraced this particular function, for they quickly recognized it as an opportunity to affirm their elevated social status and mobility as well as nurture the bond with their families.

Attaching a location to a user's status update adds further information or cues through which a message can be interpreted. When Judy posted from Heathrow Airport, it was evident that she was on her way to visit her family in the Philippines. When Donna's status declaring tiredness was tagged next to the name of a well-known designer outlet near London, the obvious interpretation was that her tiredness was the result of shopping, as opposed to a long or late shift at the care home where she works. Although such practices were common and done without much thinking, my respondents were aware that they were letting out additional cues about their whereabouts and, ultimately, about their newfound social status. Location can also be declared via the practice of 'tagging' users to photographs, especially when these are of well-known monuments or landmarks. When Donna visited the Tower of London she was 'tagged' in several pictures by her sister-in-law. Even posting standalone photographs of landmark buildings can confer location: this is how Maria-Theresa announced her trip to Disneyland Paris.

The migrants were eager to receive similar information from their families, but partly because of structural limitations, such as fewer smartphones, their locative practices were considerably more limited. Still, some of the family members who had been left behind geolocated their messages, so were thus able to create a reciprocal peripheral awareness of each other's physical movements.

\section{Ambient context and ambient communities}

Being always 'on' enables not just the peripheral awareness of one's own family members and close friends, but of several others to whom a user is connected with in 
social media. Given that the 13 subjects of my study had an average of 547 Facebook 'friends' (Janice had the most with 867 and Joan the fewest with 252), their 'news feed' was filled with updates from all these other contacts. 'Hiding' friends (choosing to make the news updates certain 'friends' invisible while maintaining the publicly articulated connection) was very uncommon among my respondents. Furthermore, depending on their own privacy settings as well as those of their Facebook 'friends', they had potential access to material posted by hundreds of additional users. For example, when Janice's daughter is 'tagged' in a photograph uploaded on Facebook by one of her university friends, her mother is usually able to see the picture as well as any comments. Janice's daughter and many of her friends keep their privacy settings open allowing 'friends of friends' to access their profiles therefore making their content available to multiple and unknown audiences. This practice was representative of most informants.

Participants did not complain about other people's status updates and images diluting information about their families and close friends. In fact, on several occasions many of these items of news provide the context through which to interpret the communications with relatives. The constant stream of news available to participants through their smartphones offered several cues that were invaluable for understanding the meaning of individual posts by significant others. These cues are visual, textual, emotional or even aural in the case of videos. When participants see content provided by 'friends of friends' (for example, Janice's daughter's friend) they treat it as an opportunity to peek into the lives of their teenage or young adult children. Donna, for instance, often told me that since she cannot be at the school gate to pick up her sons or to meet her sons' friends on a regular basis, she relies on Facebook as a substitute for those kinds of experiences.

Of course, the unintended and potentially infinite number of recipients of social media content can cause what boyd (2010: 51) calls 'context collapse', which can lead to misunderstandings and conflicts. Although social media users post with a specific implied audience in mind, they can almost never control who will ultimately read their posts (Marwick and boyd 2011). Informants occasionally reported such experiences, which often caused embarrassment or even conflict and trauma. In an earlier publication (Madianou and Miller 2012) we discuss at length the shock of a teenage boy on seeing photographs in his mother's profile when she contacted him through social media after spending many years of silence abroad. There are implications for privacy here, as discussed in the next section.

It is important to recognize that the stream of news from friends in the Philippines and transnationally (all respondents had family based in several different countries) was valuable in its own right. Facebook and other social media provide opportunities to revitalize old family and other networks (Miller and Slater 2000). Participants put a lot of effort into rediscovering old friends and finding out about their current circumstances. Judy and Janice spent hours on Facebook organizing reunions for their school and college friends. Given many participants experience stressful and long working hours as well as loneliness, it is easy to see how Facebook can become an absorbing social space. It is clear that what is going on here is not just an ambient awareness of 
significant others but also a sense of 'ambient community'. The value of ambient community is contextual but also ontological, contributing to participants' identities as these are articulated through their various networks. Ambient community also immerses participants into emotional and moral spaces. This is particularly evident during crises, for example, the heavy monsoon rains that flooded Manila in August 2012, when many participants became deeply absorbed in the rescue operations and extent of the devastation. Their social media feeds resembled a moral space of obligation towards the victims and eradicated almost any other topic of conversation for days. The constant flow of images and interactions between migrants and their families and friends revealed how life in the Philippines can become an ambient background to life in England.

\section{The burden of ambient co-presence: conflict, surveillance and normativity}

This background presence of others is not always welcome. Indeed, it can be the source of problems and conflict, as is evident in the story of Judy. When Judy separated from her boyfriend, she continued to receive his status updates on Facebook. Ambient co-presence meant that, although the relationship had ended, her ex-partner was still part of her daily life in a way that Judy could not easily control. His presence continued despite their separation and Judy told me that 'unfriending' him 'didn't even cross her mind' as she felt that deleting him from her list of 'friends' would have been inappropriate. Eventually, Judy decided to 'hide' her ex-partner (by selecting not to receive his updates in her news feed), but even that strategy did not prevent his news popping up into her news feed when, for example, one of their friends in common commented on his posts. Judy's example confirms that privacy in social media is no longer an individual matter, but dependent on relationships between individuals within networks - what Marwick and boyd (2014) call 'networked privacy'. Polymedia interactions require new strategies for managing privacy, which in turn determine how users navigate media environments.

There are several ways in which the presence of others can be problematic, if not tyrannical. The boundaries between ambient co-presence, monitoring and surveillance are often blurred. When Maria-Theresa leaves Skype on while asleep it is possible to interpret this - at least to an extent - as an act of surveillance and monitoring, however banal: hearing the characteristic sound of her boyfriend appearing online is confirmation that he returned home at the agreed time, or that he woke up at his regular time. Maria-Theresa employs the full functionality of Skype - webcam and voice communication as well as the humble 'status symbol' - to manage the challenges of having a long-distance relationship. She told me that her own 'status symbol' is always turned to 'available' or 'online' and that she's agreed with her boyfriend to do the same when he is at home. The status symbol (which can be 'online', 'away', 'do not disturb' or 'invisible') is information rich. Seeing one's contacts appear online (or fade offline) provides a sense of their movements and their daily rhythms, which can be very meaningful in the absence of face-to-face interaction. The 'chat' function on Facebook provides similar information (online/offline), which can be equally revealing. 
Not all participants agree to such monitoring willingly. Donna scours her sons' Facebook profiles for cues and raises any concerns she has about them with her sister. Mimi first suspected that her son had dropped out of school because his status symbol was 'on' when he was supposed to be in class. Mimi was worried enough to confront her daughter who finally confessed that her brother spent his days at home playing video games. The revelation, which caused conflict in the family, was devastating for Mimi, who had migrated so that she could afford to pay for her children's private education. Communication practices reflect the relationship between the individuals concerned, which is asymmetrical in the case of parents and children. Teenagers are considerably more likely to feel 'spied on' by their parents than the other way round, as research from various contexts confirms (Madianou and Miller 2012; Marwick and boyd 2014). Despite the monitoring and surveillance potential of social media, on the whole participants did not express strong concerns about intrusion confirming views that privacy is culturally and contextually defined (Dourish and Bell 2011; Madianou and Miller 2012).

Surveillance also occurs at a collective level when normative patterns of behaviour emerge in social media, especially in response to dramatic events such as a natural disaster. As noted above, during the August 2012 monsoon floods, discussions about rescue operations, the extent of the devastation in Metro Manila, requests for help and prayers of hope inundated the migrants' social media spaces. ${ }^{4}$ Online ethnography revealed an almost universal preoccupation with the floods, at least during the first few days of the disaster, which virtually obliterated any other type of conversation or activity (such as playing games on Facebook). People do not necessarily express normative behaviour openly; it becomes evident in practice, in this case by excluding otherwise normal activities as if they were inappropriate or distasteful. Ambient co-presence, which entails a peripheral awareness of others, becomes the tool through which normative behaviour becomes palpable. This example reveals a dimension of social surveillance (however benign) that rests on the heightened awareness of what others think and feel.

\section{Ambient co-presence and emotional reassurance}

Ambient co-presence is not only associated with heightened conflict as Judy's example suggested. The peripheral awareness of the activities and the routines of others made possible through the rich environment of polymedia often leads to a low level of emotional reassurance. Ambient co-presence extends the possibilities of co-presence at a distance. Even though it rests on indirect communication, ambient co-presence can have powerful emotional consequences.

The reassuring nature of ambient co-presence can be understood when considering the anxiety that often emerges in its absence. When Donna noticed that her sons had been inactive online for several days, she became worried. She even called her teenage son on his mobile phone - something she has rarely done since she started using social media and Skype quite heavily. Similarly, several participants became worried when their significant others did not appear 'online' at a usual time. If one expects one's 
partner or child to come home at a regular time and to switch on his or her laptop and automatically $\log$ on to Skype, then this establishes a pattern. When an established pattern is disrupted, it becomes a source of concern or anxiety, which may be accentuated by physical distance as it is difficult to check on a relative to find out what is going on.

A metaphor that can shed light on the reassuring nature of ambient co-presence in the context of deterritorialized relationships comes from physical, geographical co-presence. Ambient co-presence can provide a comforting background awareness of others appearing and disappearing online, waking up or returning from work, announcing their visit to a shopping mall or sharing pictures of their dinner. It is comparable to the familiar sounds of family members going about their parallel activities in one's home without necessarily interacting with each other but being profoundly aware of the others' presence, such as the soothing sounds of someone cooking in the kitchen, or of a child playing in her room. Although indirect, ambient co-presence allows for the regular presence of distant others in the lives of migrants. Compared with the pre-Web 2.0 era participants now have access to a plethora of details about their families' whereabouts, activities, food, clothes and other possessions. When Janice showed her daughter her new dress on Skype, her daughter retorted, 'but I've already seen the dress, you were wearing it in the picture you posted yesterday.' Today, we are increasingly taking for granted the ordinariness of seeing one's mother or daughter in a new dress on one's smartphone screen. However, this was not so a few years ago when the only visual cues afforded to migrants were photographs, whether attached to an email and sent and received via an internet café, or posted through a letter, which might take weeks to arrive.

This does not imply that intense emotions have no place in transnational communication in polymedia environments. As we saw earlier, conflict is clearly present in transnational families. The ambient awareness of domestic rhythms can only be reassuring when family members enjoy good relationships. When there are tensions, frequent or constant communication can reveal problems that make situations fraught and difficult. The difference with the past situation is that conditions of 'always on' reveal connectivity problems more easily. Because communication takes place in the complex environment of polymedia, social cues are information rich. As we saw earlier, the functionality of platforms (for example, the status sign) can also be revealing. It is more difficult to conceal news today than in the days of letter writing when problems were seldom mentioned (Madianou and Miller 2012). Furthermore, once problems surface, the constant communication afforded by polymedia provides opportunities, at least potentially, to discuss and negotiate. So, although conflict and arguments continue to be part of transnational family life, as in every family, the intensity of the arguments is potentially assuaged because there are more opportunities to address their causes and, indeed, more opportunities to have arguments. Some participants reported that arguments may be more frequent, but less intense.

Of course, the exact contours of mediated conflict in polymedia environments will vary with each relationship, as well as the stage of a relationship. As Donna's earlier example demonstrates, her relationship with her boys changes as they become teenagers. It is not communication technologies that determine conflict or its mitigation, but rather the way people exploit technological affordances to manage 
specific relationships. Therefore, the conclusion that ambient co-presence may assuage conflict should be treated with caution as much depends on the actual relationships and how these intersect with technological affordances. To the extent that it is possible to generalize, we can say that ambient co-presence can accentuate the quality of relationships. For example, someone in a shaky relationship (as Judy's earlier example suggested) may find his or her partner's activity on Facebook a source of jealousy and friction. For those who enjoy relatively strong relationships, ambient co-presence can be associated with low-level emotional reassurance.

\section{Conclusion}

In this article, I sketched the contours of a new type of indirect interaction at a distance. Ambient co-presence is the peripheral, yet intense, awareness of distant others made possible through the ubiquity and affordances of polymedia environments (Madianou and Miller 2012). Drawing on a long-term ethnography of UK-based Filipino migrants and their communications with their transnational families, I observe that the popularization of smartphones and tablets as well as wireless services have made possible an 'always on' culture of ubiquitous connectivity. Being online, which for participants often means being on social media, becomes increasingly taken-forgranted. The functionalities of a social networking site (SNS) such as the 'news feed', combined with the portability of internet-enabled devices, mean that users can be peripherally aware of the actions and daily rhythms of their significant (and not so significant) others on a constant basis and while on the move. Locative technologies and practices contribute rich information about the users' mobility and social status. Ambient co-presence does not replace other types of mediated interactions, but rather supplements them, thus potentially enriching the ways in which transnational family members 'do family' (Morgan 1996). However, the pervasive nature of ambient co-presence may partly explain why some participants reported a reduction in direct mediated communication. Crucially, ambient co-presence emerges as a dynamic practice integral to how users navigate the environment of polymedia to manage and maintain their relationships. This challenges accounts that reading social media news feeds is 'passive content consumption' (Vitak 2014).

Ambient co-presence is not just about the peripheral awareness of significant others, but also of wider social circles. 'Ambient community' provides social context, while it enhances users' sense of belonging by immersing them into emotional and moral spaces. Although the participants in the study often embraced the experience of ambient community, I recognize that there are strong social surveillance implications, which, although culturally produced, can potentially become oppressive at an individual level. Being immersed in a social network calls for novel strategies for managing privacy and individuality, which in turn determine how users navigate polymedia.

Ambient co-presence can have negative implications at an interpersonal level as it can heighten conflict, especially through opportunities for surveillance. Participants with weak or unstable relationships experienced an increase in conflict. By contrast, those who enjoy strong relationships associated ambient co-presence with low-level 
emotional reassurance, which can potentially open up new ways of being together at a distance. Like other forms of sociotechnical intersection, communication technologies accentuate what already exists but are unable to correct what are ultimately social problems. Ambient co-presence may give transnational families additional ways of 'doing family', but will not solve separation or other relationship problems. Given that all my participants were still in the UK eight years after I first met them, suggests that the experience of ambient co-presence may, to extend an argument developed elsewhere (Madianou 2012), be a contributory factor towards justifying their decisions not to return to the Philippines.

Not all migrants have access to the rich communicative environments of my Filipino participants. The argument developed in this article applies to members of transnational families who have access and skills to exploit a range of communication possibilities. Although several migrant groups, because of their strong communication needs, are sophisticated users of new media (Fortunati et al. 2012), digital inequalities persist among marginalized populations (Madianou 2015). At the same time, the relevance of the concept of ambient co-presence extends beyond migrant populations. Most personal relationships today combine face-to-face and online interactions that include the indirect mediated communication that sustains ambient co-presence. Several of the examples of communication between parents and teenagers, and between romantic partners, discussed here resonate with research in Western contexts (Baym 2010; Marwick and boyd 2014). The development of specific online norms relating to privacy and surveillance may be culturally specific, but the wider argument about the peripheral awareness of others and the ways individuals exploit the functionalities of polymedia to manage the challenges of ambient co-presence are of wider relevance. This is an example of how research with migrants can generate theory that extends beyond the confines of migration research. The participants in this study, because of their prolonged separation from their families, experienced an extreme form of dependency on mediated communication, which helped to crystallize the social consequences of media environments.

\section{Acknowledgement}

The work was supported by the Economic and Social Research Council (grant number RES-00022-2266).

\section{Notes}

1. Although users are able to approve the tags by SNS 'friends' which appear on their profile, their images are still likely to circulate among users who are part of the same social network of friends.

2. The exact ordering of a user's 'news feed' is determined by algorithms adding a further reason why users cannot control their content.

3. According to Ofcom, the UK is a 'smartphone society' with more than two-thirds of adults using a smartphone. Source: http://stakeholders.ofcom.org.uk/market-data-research/marketdata/communications-market-reports/cmr15/uk/.

4. For similar observations during Typhoon Ondoy, see Ong (2015). 


\section{References}

Asis, M. M. B. (2008) 'The Philippines', Asian and Pacific Migration Journal, 17 (3-4), 349-78.

Baldassar, L. (2008) 'Missing kin and longing to be together: emotions and the construction of co-presence in transnational relationships', Journal of Intercultural Studies, 29 (3), 247-66, doi: 10.1080/07256860802169196.

Baldassar, L., C. Baldock and R. Wilding (2007) Families caring across borders: transnational migration, ageing and long distance care, Basingstoke: Palgrave Macmillan.

Baym, N. (2010) Personal connections in the digital age, Cambridge: Polity

boyd, d. (2010) 'Social networking sites as networked publics: affordances, dynamics, implications', in Z. Papacharissi (ed.) A networked self, New York: Routledge.

boyd, d. (2012) 'Participation in the always on lifestyle', in M. Mandiberg (ed.) The social media reader, New York: NYU Press.

Cabanes, J. and K. Acedera (2012) 'Of mobile phones and mother-fathers', New Media and Society, 14 (6), 916-30, doi: 10.1177/1461444811435397.

Connor, P., D. Cohn and A. Gonzalez-Barrera (2013) 'Changing patterns of global migration and remittances', Pew Research Center report, available at: www.pewsocialtrends.org/files/2013/ 12/global-migration-final_12-2013.pdf.

Dourish, P. and G. Bell (2011) Divining a digital culture: mess and mythology in ubiquitous computing, Cambridge, MA: MIT Press.

Ellison, N. B. and d. boyd (2013) 'Sociality through social network sites', in W. H. Dutton (ed.) The Oxford handbook of internet studies, Oxford: Oxford University Press, 151-72.

Fortunati, L., R. Pertierra and J. Vincent (eds) (2012) Migrations, diaspora and information technology in global societies, Abingdon: Routledge.

Harper, R. (2010) Texture, Cambridge, MA: MIT Press.

Haythornthwaite, C. (2005) 'Social networks and internet connectivity effects', Information, Communication \& Society, 8 (2), 125-47, doi: 10.1080/13691180500146185.

Hermida, A. (2010) 'Twittering the news: the emergence of ambient journalism', Journalism Practice, 4 (3), 297-308, doi: 10.1080/17512781003640703.

Hondagneu-Sotelo, P. and E. Avila (1997) " I'm here, but I'm there": the meanings of Latina transnational motherhood', Gender and Society, 11 (5), 538-71, doi: 10.1177/089124397011 005003.

Hutchby, I. (2001) 'Technologies, texts and affordances', Sociology, 35 (2), 441-56, doi: $10.1177 / \mathrm{S} 0038038501000219$.

King-O'Riain, R. C. (2014) 'Transconnective space, emotions, and Skype', in T. Benski and E. Fisher (eds) Internet and emotions, London: Routledge, 131-43.

Licoppe C. (2004) “"Connected" presence: the emergence of a new repertoire for managing social relationships in a changing communication technoscape', Environment and Planning D: Society and Space, 22 (1), 135-56, doi: 10.1068/d323t.

Licoppe, C. (2013) 'Merging mobile communication studies and urban research: mobile locative media, "onscreen encounters" and the reshaping of the interaction order in public spaces', Mobile Media and Communication, 1 (1), 122-8, doi: 10.1177/2050157912464488.

Ling, R. and B. Yttri (2002) 'Hypercoordination via mobile phones in Norway', in J. E. Katz and M. Aakhus (eds) Perpetual contact, Cambridge: Cambridge University Press, 139-69.

Madianou, M. (2012) 'Migration and the accentuated ambivalence of motherhood: the role of ICTs in Filipino transnational families', Global Networks, 12 (3), 277-95, doi: 10.1111/ j.1471-0374.2012.00352.x.

Madianou, M. (2014) 'Smartphones as polymedia', Journal of Computer-Mediated Communication, 19 (3), 667-80, doi: 10.1111/jcc4.12069.

Madianou, M. (2015) 'Digital inequalities and second-order disasters', Social Media and Society, 1 (4), doi: $10.1177 / 2056305115603386$. 
Madianou, M. and D. Miller (2012) Migration and new media: transnational families and polymedia, Abingdon: Routledge.

Madianou, M. and D. Miller (2013) 'Polymedia: towards a new theory of digital media in interpersonal communication', International Journal of Cultural Studies, 16 (2), 169-87, doi: $10.1177 / 1367877912452486$.

Markopoulos, P., B. de Ruyter and W. Mackay (eds) (2009) Awareness systems: advances in theory, methodology and design, London: Springer.

Marwick, A. and d. boyd (2011) 'I tweet honestly, I tweet passionately: Twitter users, context collapse, and the imagined audience', New Media Society, 13 (1), 114-33, doi: 10.1177/ 1461444810365313.

Marwick, A. and d. boyd (2014) 'Networked privacy: how teens negotiate context in social media', New Media and Society, 16 (7), 1051-67, doi: 10.1177/1461444814543995.

Miller, D. and D. Slater (2000) The internet: an ethnographic approach, Oxford: Berg.

Morgan, D. H. J. (1996) Family connections, Cambridge: Polity.

Nedelcu, M. (2012) 'Migrants' new transnational habitus: rethinking migration through a cosmopolitan lens in the digital age', Journal of Ethnic and Migration Studies, 38 (9), 1339-56, doi: 10.1080/1369183X.2012.698203.

Ong, J. C. (2015) The poverty of television, London: Anthem.

Papacharissi, Z. (2009) 'The virtual geographies of social networks: a comparative analysis of Facebook, LinkedIn and ASmallWorld', New Media and Society, 11 (1-2), 199-220, doi: $10.1177 / 1461444808099577$.

Parreñas, R. (2001) Servants of globalization, women, migration and domestic work, Stanford: Stanford University Press.

Parreñas, R. (2005) 'Long distance intimacy: class, gender and intergenerational relations between mothers and children in Filipino transnational families', Global Networks, 5 (4), 317-36, doi: 10.1111/j.1471-0374.2005.00122.x.

Parreñas, R. (2008) The force of domesticity, New York: New York University Press.

Peng, Y. and O. Wong (2013) 'Diversified transnational mothering via telecommunication', Gender and Society, 27 (4), 491-513, doi: 10.1177/0891243212473197.

POEA (Philippine Overseas Employment Administration) (2005) 'Overseas Employment Statistics', Manila: POEA, available at: www.poea.gov.ph/stats/OFW_Statistics_2005.pdf.

POEA (2010) 'Overseas employment statistics 2010', Manila: POEA, available at: http://poea.gov.ph/stats/2010_Stats.pdf.

Thomas, W. I. and F. Znaniecki (1984) The Polish peasant in Europe and America: a classic work in immigration history, edited and abridged by E. Zaretsky, Urbana: University of Illinois Press.

Tong, S. and J. Walther (2011) 'Relational maintenance and computer-mediated communication', in K. B. Wright and L. M. Webb (eds) Computer mediated communication in personal relationships, New York: Peter Lang, 98-118.

Turkle, S. (2011) Alone together, New York: Basic Books.

Uy-Tioco, C. (2007) 'Overseas Filipino workers and text messaging', Continuum: Journal of Media and Cultural Studies, 21 (2), 253-65, doi: 10.1080/10304310701269081.

Vertovec, S. (2004) 'Cheap calls: the social glue of migrant transnationalism', Global Networks 4 (2), 219-24, doi: 10.1111/j.1471-0374.2004.00088.x.

Vitak, J. (2014) 'Connecting in the Facebook age: development and validation of a new measure of relationship maintenance'. Paper presented at the International Communication Association 64th Annual Conference, May, Seattle, WA, available at: http://goo.gl/rBjPwS.

Wajcman, J., M. Bittman and J. Brown (2008) 'Families without borders: mobile phones, connectedness and work-home divisions', Sociology, 42 (4), 635-52, doi: 0.1177/003803 8508091620 .

Wilding, R. (2006) "Virtual" intimacies? Families communicating across transnational contexts', Global Networks, 6 (2), 125-42, doi: 10.1111/j.1471-0374.2006.00137.x. 